\title{
Challenges of Combating Illegal Immigration as Cross Border Crime Among Southern Africa Development Community (SADC) Member States: Case Study of Zambia
}

\author{
Prosper $\mathrm{Ng}$ 'andu \\ Graduate Studies, University of Zambia, Great East Road Campus, P.O Box 32379, Lusaka, Zambia
}

\begin{abstract}
The phenomenon of Illegal immigration has become an increasing source of concern Worldwide, though they may be of benefit to either the sending or receiving country. Most SADC member states were grappling with illegal immigration. The three (3) years case study research established that cases of illegal immigrants in Zambia were the order of the day; either dozens or more were being intercepted and arrested whichever at border when entering the country without valid travel documents or staying in the country without required documents. It is in back drop that prompted a supposition that SADC states in the case of Zambia has challenges to combat the influx of illegal immigrants. Based on 36 months case study methodology research, this article aim to analyze the challenges SADC states (Zambia) were encountering in combating illegal immigration. The study established severe challenges which included; long stretch of borders to which some were porous; lack of political will; lack of manpower for immigration officers; absence of migration policy; bribery/corruption; inadequate sensitization and lack of skill. The article is built on the primary and secondary data collected from 37 respondents and literature. Purposive, Cluster, Snowball and random sampling were used to select respondents to whom the method of semi-structured, in-depth interviews and observation was administered. Meanwhile, thematic analysis was employed for both primary and secondary data. The study recommended that the combating of the phenomenon calls for holistic approach.
\end{abstract}

Keywords: Illegal immigration, SADC, Zambia, Globalization, Cross border Crime, Cosmopolitanism and Communitarianism.

DOI: $10.7176 / \mathrm{IAGS} / 74-02$

Publication date:July $31^{\text {st }} 2019$

\section{Introduction}

Since the 1970s politicians, policy makers and various stakeholders worldwide have been engulfed with great concern over increasing reports of Illegal immigration (Campbell, 2006). Poverty has forced professionals and non-professionals to take desperate steps to survive and improve their living standards elsewhere. The phenomenon has not spared developed world. Boustan \& Abramitzky, (2017) the United States of America also experienced increase of mass migration which was linked to the shift from sail to steam technology in the midnineteenth century, and a consequent decline in the time of trans-Atlantic passage.

The phenomenon of illegal immigrations in Zambia is not exceptional, just like the cases are in other SADC member states such as South Africa, Namibia, Botswana, and other countries across the global. Zambia Daily Mail (Jan 13, 2015) " in Zambia, hardly a month passes without news of a dozen or more foreign nationals being arrested mostly for illegal entry or illegal stay in Zambia or both". The Zambia Immigration and Deportation Act 18 of 2010 regulates movement and stay of foreigners in Zambia, News of their illegal entry into the country in containerized trucks, among other unorthodox means of entry, is not strange anymore. These have always threatened the security of Zambia as it is difficult to categorize the genuine immigrants who avoid going through immigration procedures (Xinhua, 2006). The primary reasons for illegal border crossing in most SADC states is attributed to factors inter alia; inter or intra-national conflicts; variation in economies among member states; and vastness of common borders which leads to certain border to be vulnerable and porous (Wafule, 2013). Despite, Zambia having repealed the immigration and Deportation Act in 2010 and the strides it making with other SADC member regulate the legal movements and stay of foreign nationals, the scourge of illegal immigration remains a security challenge.

\section{Background of illegal immigration}

The emergency of globalization coupled with the end of the cold War has been the major drivers to migration. Nkurayija, (2011) the two elements were causing havoc to security well being of the states to contain the rapidly increasing cases of cross border crimes that include illegal immigration. Some scholars have defined Globalization as "a process of worldwide integration of economies and societies" (Akinyemi, 2013).

Globalization permits illegal immigrants to cross the border unhindered even continue engaging in illicit activities like terrorism, robbery with impunity, thereby, negatively affecting the social-economic development and security of lives and property. However, the proponents of globalization Stiglitz (2002, p. 3) argues that, 
"globalization is helping many countries to grow far more quickly than they would otherwise have done

The ramification of globalization has precipitated illegal immigration in the sense that traditional borders have become vulnerable and free movement of people has increased. Some of the people who illegally cross borders have illicit intentions which pose a danger to the security of receiving country, hence the emphasis by Simmons that the securities of the receiving nations need not to be endangered.

The traditional borders are ripped off due to globalization and end of the cold war. This situation is not unique to traditional borders in the Southern Africa Development Community (SADC) region. The SADC member states are part of other global States that are facing daunting pleasure of managing illegal immigrants.

Williams (2011) stress that the movements of people across political boundaries in recent years has generated considerable debate in Africa and globally. At the international level, issues of migration are governed by United Nations (UN) Convention on the Protection of the Rights of Migrant Workers and members of their families of 1990, as well as the International Labor Organization (ILO) Convention 143. In Africa, these issues of migration are also dealt with through national legislation, bilateral and multi-lateral agreements and between countries or among states as well as various protocols developed by regional bodies such as Economic Community of West Africa (ECOWAS) and SADC.

SADC members, since inception of the organization, have formulated, ratified and signed a number of protocols, which include: Protocol Against Corruption 2001, Protocol on Combating Illicit Drug Trafficking 1996 and Protocol on the Facilitation and Movement of Persons 2005, (SADC Protocol, 2012). Zambia utilizes an Immigration and Deportation Act 18 of 2010 to monitor and regulate the movement of foreign nations (Immigration and Deportation Act, 2010).

\subsection{Definition of Illegal Immigration}

An illegal immigrant can be defined as "a person who enters a country of which he/she is not a citizen without demonstrating at the point of entry that he/she posses' legal documents that justify such entry" (Campbell, 2014). In fact, illegal immigration constitutes a criminal offence for which, if apprehended, could carry the full penalty of the particular country immigrations law. Not surprisingly, in certain countries illegal immigration is treated as a very seriously criminal behavior and persons accused of attempting or making an illegal entry may be treated harshly. When such a person is apprehended, it is either is prosecuted through the courts of law and later deported or removed if proven guilty or can be removed to the country of origin without being trialed by the courts of law.

In researching on the Irish Institutional Discourses of Illegal Immigration, (Burroughs, 2012) defines illegal immigrants as:

Any person, who does not, or no longer, fulfils the conditions for entry to, presence in, or residence on the territories of the Member States of the European Union. A non-national who enters, or seeks to enter, or has entered the State unlawfully (Illegal Immigrants). All non-national persons who are in the State without necessary permission are unlawfully present, except for asylum seekers, convention refugees and their families and programme refugees. An illegal immigrant is a person whose presence in the State is otherwise than in accordance with our immigration laws. Obviously the term covers persons who entered the State in breach of those laws - either covertly or using false documentation. However, it also covers persons who entered lawfully, but remain beyond the duration of the permission given, or who, although required to adhere to certain conditions (e.g. prohibited from working), are in breach of those (p.17).

These definitions of illegal immigrants are very broad and any attempts to classify illegal immigration reveal that it is not a static category that is easily definable. Illegal immigrants can be of any age, gender, nationality, or profession and any simplification, such as illegal immigrants are young single males, can be misleading. The illegal immigration cannot be determined by gender, age, nationality or profession, illegal is illegal besides the ascription.

The definition by Burroughs that an illegal immigrant is non-national who enters, or seeks to enter, or has entered the state unlawfully or all non-national persons who are in the state without necessary permission has missed a point. Some foreign nationals are tempted to enter another country by human smugglers; hence it is incorrect to cluster such victims as illegal immigrants. The definition may be supported in countries that lack legal framework of human smuggling or trafficking, as it becomes difficult to prosecute such offenders in the absence of legal framework.

Solomon (2000) also defines illegal immigrant as "a person living in a foreign land or country without valid immigration documents and devote much time to evading the authorities; any attempt to count them is speculative". In the case of Zambia, illegal immigration constitutes a criminal offence for which, if apprehended, can be prosecuted under Immigration Act 18 of 2010 (Immigration and Deportation Act, 2010). To combat illegal immigration efficiently and effectively, we need to know their types and the causes the precipitate such movements. 


\subsection{Typologies of illegal immigration}

Illegal immigration is in diverse types or illegal status concerning persons' movement and residency. Migrants possibly will cross international borders devoid of appropriate documents, or sometimes they cross borders through legal documents nevertheless they overstay their visas in the country of destination therefore, they are considered as illegal migrants. In other instances, legal migrants could be tagged as illegal migrants owing to changes in legislations related to precise nationalities or the change of the regulations related to work permits or residence (Zohry, 2011). Main types of illegal migration could be summarized in the following;

\subsubsection{Illegal international Borders Crossing}

Illegal border crossing from the country of origin to the country of destination, directly or through a transit country, without appropriate documents required by the authorities of the transit country, if applied, and the country of last destination. Contributing to the need of resolving illegal cross border immigration (Machecka et al, 2015) stress that illegal international crossing also involves those who arrive in a clandestine fashion in foreign country including migrants who are generally perceived to have crossed a country's border without required documents. The illegal means of crossing the border include using the human smugglers such as cross border truck and bus drivers, middle men and conmen who work in cahoots with the corrupt police and immigration officers on both sides of the border. The illegal border crossing was one of the challenges being faced with most SADC states. Lusaka times (Sept. 2015\& October 2017) report that Zambia experience high number of illegal cross border immigration who include 100 Ethiopians and 70 Somalis who were intercepted and arrested in Serenje in the Central province after illegally crossing Nakonde border post using containerized trucks.

\subsubsection{Overstaying Visa}

Illegal immigration by overstaying (Zohry, 2011) is where the visa duration expires but the immigrant does not bother to renew. The immigrants crossed legal border from the country of origin to the country of destination, directly or through a transit country, with appropriate documents required by the authorities of the transit country, if applied, and the country of last destination, but the duration expires.

Page (2019) reports that in New York 2019, the Center for Migration Studies released a report on migration statistics indicating that US undocumented population continued to fall from 2016 to 2017, and Visa overstays significantly exceeded illegal crossings for the seventh consecutive Year, shows that the majority of illegal immigration is attributable to persons who overstay their visa versus those who cross the border without a proper entry process and inspection.

In an operation clean up in 2017, a combined team of Zambia immigration officers and other security personnel conducted in Lusaka towns and compound of, Chaise Compound, Chilenje and Kamwala trading area, 136 illegal immigrants inter alia; Chinese, Somalis, Indians, Nigerians, Burundi, Kenyans and Zimbabweans were arrested for overstaying contrary to Immigration and Deportation Act No 18 of 2010 (Lusaka Times, 2017).

Illegal immigration through overstaying by visa affects also other SADC members not only Zambia. In 2018, Mozambique's National Immigration Service (SENAMI) repatriated 1,337 illegal migrants in the first half of the year compared with 2,732 in the same period in 2017. The large of these cases, representing 68 per cent of the total, were removed for overstaying. This refers to remaining in the country longer than the period stipulated by the visitor's entry visa, or in the visa waiver agreements (Fernandes, 2018).

3.2.3 Illegal Work: An illegal immigrant by working is a situation whereby someone crosses legal border from the country of origin to the country of destination, directly or through a transit country, with appropriate documents required by the authorities of the transit country, if applied, and the country of last destination, but working illegally when the visa is issued for other purposes such as tourism, medical treatment, or any other reason that doesn't permit visa holder to join the labor market of the country of destination. The Immigration and Deportation Act No 18 of 2010 mandates immigration officers in Zambia to monitor and regulate foreigner nationals granted with work permit not to abrogate the rules. They should not engage in other jobs other than the one prescribed on the permit and that the employer has to apply for a permit before the employee arrives in the country to take up such a position. Therefore, should any foreign employee violates that then is reliable to fine and sometimes revocation of the permit.

In the case of government, volunteer and missionaries workers the permits can be applied whilst in Zambia. Nonetheless, should anyone found working without a permit, or expired work permit then such a person will be treated as illegal immigrant.

3.2.4 Illegal Stay due to Changes of Laws and Regulations: this type of illegal immigrants legally cross the border, legal residence, but the laws that regulate residence change affect a proportion of legal migrants and label them as illegal migrants, usually with a deadline for this category to legalize their status or to leave the country. Amuedo-Dorantes et al (2013) stress that changes in national laws and policies can revolve regular migration into irregular migration, and vice-versa. The category of migrants can change during their journey and stay in the country of transit/destination, which makes it tricky to have a comprehensive picture of irregular migration and the profiles of irregular migrants. Terms such as "irregular", "undocumented", and "unauthorized" are used 
interchangeably. Illegal immigration affects countries across the global.

\subsection{Causes of illegal immigration}

Migration is a global phenomenon caused not only by economic factors, but also by social, political, cultural, environmental, health, education and transportation factors. It commonly takes place because of the push factor of less opportunity in the socio-economic situation and also because of pull factors that exist in more developed areas (Thet, 2015).

\subsubsection{Push factors.}

The push factors are situations or prevailing conditions in someone's country or national those compel such a person to immigrate to another place by crossing political boarders. These factors could be poor social economy, unemployment, low real income, ethnicity, low currency, competition with expatriates. When the country or state experience poor economy, citizens are subject to suffering and eventually others opt to seek Green Avenue easy where. Kinbacher (2006) the same apprise when unemployment levels go high people would leave and search for employment in another states. The factor of ethnic or tribalism bleeds civil war, and when such occurs the victims pushed and flee to other States for safe heaven.

Hutchison (2015) cites that Social push factors include lack of social mobility and job restrictions. For example, in the 1800 's, Italians were restricted by social class. If you were born a peasant, you would always remain a peasant. No matter how hard you worked, there was no way to move up the social ladder. As a result, many Italians began to immigrate to the U.S. Other social factors that make people decide to leave their homes include epidemics and starvation. There were widespread epidemics of cholera and malaria in Europe in the 1800 's. The Irish potato famine in 1845 enforced many Irish to disappear their homeland.

Political factors that drive people from their mother country include persecution and government restrictions on citizens (Hutchison, 2015). The Jews were persecuted for many years in Europe, especially during World War II. It was felt imperative many to leave and discover new homes in the U.S. and other countries. Communist governments in Europe and Asia placed many restrictions on the people there. Many people from Poland, Russia, and other countries decided to leave to find freedom.

Thet, (2015) economic push factors of immigration include poverty, overpopulation, and lack of jobs. Many Irish, Italians, and Germans determined to go and survive in the U.S. Social, political, and economic push factors cause citizens to be dissatisfied with life in the countries they were born in. Because of these factors, many left their homelands in search of a better life somewhere else. Many chose the U.S., making this country a nation of immigrants.

\subsubsection{Pull factors}

Immigrants, on the other hand, are pulled to destination countries as they see this as offering them economic opportunities that are not available in their home countries. These immigrants range from a large number of unskilled to a limited number of highly skilled workers (Rassool et al, 2017). These are attributes that pull the victims or vulnerable from the prone States to migrate to the other States which can provide the needs. These factors include high salaries, greater job mobility, professional career, less bureau control and high standard of living.

There are many factors that push people out of the country. While affirmative action is one factor that contributes to emigration of skilled individuals, other factors include: crime, better wage offers, better quality of life and future for their children, economic stability and improved health care. These factors include: attractive salary packages, early retirement within the education sector, an opportunity to gain international work experience, an improved lifestyle and a variety of career choices (Ncube et al, 2014)

\section{Cosmopolitanism and Communitarinism theories}

Drezner (2008), other scholars of international relations have applied realism and liberalism in the study of minimizing illegal immigration arguing that the issue is of security. However, this study pursues the challenges SADC member states (Zambia as Case study) face in combating illegal immigration. It is imperative to ascertain the influences of people have and their interaction among themselves in social life. Therefore, the normative theories applied to explore the personal identity and the value of the community in which they live so that the essence of migration can be established. Migration involves not only one person. Universal human rights of migrants should not be violated against by promoting human dignity and ensure public participation is valued, hence the Cosmopolitanism and Communitarianism normative are used in this study as opposed to other international relations theories of realism and liberalism.

Zurn \& Wilde de (2016) stressed that economic, cultural and political systems in the past encircled by the borders of nation states are increasingly globalized. Politicians, civil society and other societal actors bond in publically debating issue related to globalization. Whether conflict amalgamates to form a steady cleavage depends among other issues on the degree to which they develop into ideologically underpinned. "As the foundation for such an underpinning, we recognize philosophical debates about justice between globalists and 
statists and between Universalists and contextualists as natural fabric that political capitalists energetic in the public sphere can draw upon".

On this basis, four major bones of contention have been identified that could grant the core of such ideological underpinning: "the permeability of borders; the allocation of power between levels; the normative dignity of communities; and the patterns of justification" (Steger, 2011). One ideal typical combination of those four components can be labeled cosmopolitanism combining arguments from globalists and Universalists; another communitarianism, combining statist and contextualist arguments. The more these two ideal types feature as political ideologies in public debate, the more do debates about globalization solidify into a new cleavage.

The normative theories of cosmopolitanism and communitarianism are significant theories in international relations as proponents propagate the understanding of integration of states in the international relations and interpretation of state behavior to migration. However, in this study neither realism nor liberalism has been used because these theories face challenges in global world, and this study is more of contemporary politics.

Buzan, et al (1998) argue that "the end of the Cold War, the intensification of globalization and the 'postmodern turn' have delivered powerful challenges to the orthodoxy of realism. Among the most significant of these challenges is the cosmopolitan theory advocated by David Held, Andrew Linklater and others. The normative theory looks at how national and international interests deal with the issues of refuges, illegal migration (Mark, 2015).

Illegal immigration create dilemma in host countries. There have been an increasing number of illegal immigrants arriving in SADC states and the respective governments are having challenges in combating the trend. The normative theory is an action guide which focuses on what we ought to do. This is achieved through cosmopolitanism and Communitarianism approaches. Beck (2017) points out that some scholars of International Relations stress that the two theories that guide the consideration for immigration are Communitarianism and cosmopolitanism. According to Mark (2015) the two theories seek to promote human dignity to which communitarian favors a more restrictive approach in terms of border control while, cosmopolitan advocates a more open approach of border areas.

\subsection{Cosmopolitanism}

Delanty (2006) critical cosmopolitanism is an emerging development in social theory and reflects both an object of study and a distinctive methodological approach to the social world. It is an approach that shifts the emphasis to internal developmental processes within the social world rather than seeing globalization as the primary mechanism. This signals a post-universalistic kind of cosmopolitanism, which is not merely a condition of diversity but is articulated in cultural models of world openness through which societies undergo transformation. The cosmopolitan imagination can be articulated in framing progressions and cultural models by which the social world would be constituted. It is, therefore, not reducible to tangible identities, but should be understood as a form of cultural contestation in which the logic of translation plays a central role. The cosmopolitan imagination can arise in any kind of society and at any time, but it is integral to modernity.

The first modern theory of cosmopolitanism was developed by the German philosopher Immanuel Kant during the enlightenment era of the late 18th century. His best known work is the Critique of Pure Reason (Cavallar, 2012). "Enlightenment is about thinking for oneself rather than letting others think for you" (Rohlf, 2010). The emergency of globalization that has rippled of traditional borders is not a vehicle for cosmopolitanism to advocate for free movements that emanates into illegal immigration.

\subsection{Communitarianism}

Etzioni (2015) writes:

Communitarianism is a social philosophy that, in contrast to theories that emphasize the centrality of the individual, emphasizes the importance of society in articulating the good. Communitarianism is often contrasted with liberalism, a theory which holds that each individual should formulate the good on his or her own. Communitarians examine the ways shared conceptions of the good are formed, transmitted, justified, and enforced. Hence, their interest in communities (and moral dialogues within them), the historical transmission of values and mores, and the societal units that transmit and enforce values - such as the family, schools, and voluntary associations (including places of worship), which are all parts of communities.

Amstutz (2015), one of the proponents of communitarianism, argues that norms of international law stipulate that people have a right to emigrate from their homeland but not a right to immigrate to any particular country. Communitarianism states that right of entry can be granted only by the country of destination. Communitarians advocate that states have only limited responsibilities towards outsiders. Therefore, states need to have borders and maintain sovereignty. Communitarianism sees strong nation-states as crucial, though they have moral duty to take care of immigrants. Communitarian approach is for states to maintain the country's 
society stable and well governed. This means political communities must regulate their borders.

In the Law of people's (Amstutz,2015), the philosopher John Rawls states that "international peace and justice can only be advanced through well- governed societies by which nations take care of their own people and respect the sovereignty of other states".

The underpinning of a global order is the firmness provided by nations that is concerned of their own people and respect the sovereignty of other nations. Wenar (2008) Rawls argues that some countries will accord significant respect to human rights more than other. Therefore, if human rights of allowing free passage of illegal immigrants are to be anchored in the world, then their enforcement should not depend on international institutions and Non-Governmental Organizations (NGOs). Instead such human rights need to be anchored in the actual practice of sovereign states.

Amstutz (2015, p. 2), in quoting Macedo argues that "an immigration policy cannot be considered morally acceptable in justice unless its distributive impact is defensive from the stand point of disadvantaged citizens". This does not mean assisting the migrants or promote generous immigration policies are wrong, but rather that priority should be accorded to the vulnerable political community. The vulnerable community should not suffer economically due to a larger influx of Immigrants. Political community has the right to protect the shared understandings. This means that it is not an obligation for states to protect migrants who do not share the same values with the citizens.

\section{Findings on Challenges faced by Zambia in combating illegal immigrants}

The scenario of Europe is not far-fetched with Zambia. According to the study, respondents indicated that the illegal immigration was spurred owing to various 'push' factors relating to chronic poverty, inequality, environmental degradation and conflict, as well as "pull" factors including real and perceived economic, employment, high standard of living and less bureau control. The study examined the challenges Zambia is facing to combat the illegal immigrants both at the entry point and those within the country.

The study established that the major challenges faced by Zambia to combat illegal immigrants were;

\subsection{Porous of Border Controls}

Zambia borders with eight (8) countries and the major challenge to prevent and combat illegal immigration has been attributed to the porous of the borders. The borders most of them were so vast and lacked enough manpower to police border crimes. This challenge calls for urgent attention to help in combating illegal immigration. Scholars (ISS, 2009) indicated that lack of capacity to monitor the Zambia's porous borders particularly with Angola and DRC and to a lesser extent with Zimbabwe was exacerbating the problem of illegal immigration. For instance, Luapula Province in Zambia is separated from DRC by the Luapula River, but the border is so vast thereby rendering it difficult to monitor any illegal activities.

Poorly, managed borders expose Zambia to the threats that are posed by illegal immigrants and other illegal activists. The DRC border can effectively be monitored against any cross border crime threats, with equipped powerful and serviceable speed boats, adequate manpower and adequate funds to cover the costs of fuel, lubricants and spares.

The challenge of porous border affects many states. Some Scholars have observed that taking advantage of a porous border, Palestinian nationals easily accessed Israel in search of employment and basic welfare needs; however, the influx of the Palestinians also provided easy access for terrorists to infiltrate Israel through the West Bank. This situation compelled the Israeli Government in 2002 to erect a security "fence" fifty to seventy meters (50-70ms) wide consisting two layers of Smart fence and a buffer (Isoke, 2015).

On August 14, 2014, six hundred (600) illegal immigrants of Somalia origin were apprehended in Ndola, Zambia. The group entered Zambia using illegal routes in Nakonde. The move raised questions on how porous the Zambian borders were for such a big group to enter the country unnoticed (Times of Zambia, 2014). Some respondents indicated that borders like Katima mulilo was porous such that some illegal immigrants cross into Namibia through the Zambezi River using canoes. The Katimamulilo on the Zambian side has failed to fence it as per agreement during the Joint Permanent Commission (JPC) meeting held in 2014, in Swakopmound, Namibia, thereby subjecting border to porous (Parliamentary Report, 2016).

\subsection{Historical Perspective}

Illegal immigration in Zambia was also to a certain extent conned by its historical perspective. It is sometimes difficult (ISS, 2009) for people living in the border areas to understand the concept of illegal immigration. The historical and cultural factors apply to many Zambia's border areas to which they have built families and business connections that have eventually led to other illegal immigrant from neighboring countries obtaining Zambia National Registration Cards and reside in local communities.

In Eastern Province the Malawian and Mozambican cross into Zambia for piece works in bricklaying, farming and even for fish as well as smuggling without following and prescribed immigration requirements. 
Others claim that from the custom aspect the three countries, thus Zambia, Malawi and Mozambique were one. The argument base on, for instance, Paramount Chief Kalonga Gawa Undi of the Chewa speaking people for Zambia, Malawi and Mozambique, has Sub-Chiefs in Malawi like Lukwa and he has also chiefs in Mozambique. During preparatory meetings for the Kulamba Traditional Ceremony, Mr. Justine Malowezi, who is a Chairperson in Malawi travels regularly to Mkaika in Katete District in Zambia with chewe chiefs and ' Impizis' from both countries travel and stay for three (3) weeks for Kulamba traditional Ceremony, and they are all treated like Zambians.In Western Province of Zambia, the Lozis share with the Subiya of Namibia and when there is Lusata (Mafye) Traditional Ceremony in Katimamulilo, Zambezi region of Namibia, the Lozis are invited and vice verse when there is Kuomboka Ceremony in Mongu District of Zambia, they also invite their counterparts. These nationals sometimes shift into either country or stay for some months to the extent of establishing families. This historical perspective enables illegal immigrants to circumvent personnel entrusted in the monitoring of cross border crime to act effectively.

\subsection{Lack of political will to provide adequate funding by Government}

The Zambian Parliamentary Committee of 2016 on National Security and Foreign Affairs (Report, 2016), reported that the Ministry of Home Affairs which included the Department of Immigration and Police which are mandated to police the illegal immigrants among other crimes had impediments to effective service delivery. The report spelt out that the Departments faced inadequate funding. According to the 2013-2016 Strategic Plan, the goal of the Institution was to achieve a fifty per cent $(50 \%)$, reduction in the incident of crime and sixty per cent $(60 \%)$ in other offences by 2016 . However, the Institution failed to achieve due to insufficient and erratic funding. Report (2016, pp54) funding levels to the Department were inadequate for operational and administrative requirements. As a result, removals, deportation, border patrols, chase-ups, business inspections, as well as purchase of fuels and other requirements were being affected. This was attributed to lack of political will by Government.

Some respondents interviewed at border controls lamented that it was disheartening to find that despite the revenue which was being collected at the borders through visa, the station had no motor transport or fuel which can be used by borrowing a vehicle from other department due to lack of funding. They expressed dismay that even when they receive reports of some illegal immigrant being harbored somewhere with intent to cross, it was difficult to conduct an operation because of lack of funding. Furthermore, it was demoralizing to under operations when required necessities were not provided by government hence escalation of border crimes that included illegal immigrants.

\subsection{Lack of manpower for Department of Immigration}

The Department of Immigration was facing inadequate manpower, skill in identifying migrants and technical capacity. Zambia Daily Mail (August 14, 2017), reported that Ms. Mirriam Chiyabi, Regional Immigration Officer for Muchinga attributed the escalating of illegal immigrant in Mafinga District to inadequate manpower, as the district had only two (2) Officers, yet there were a lot of crossing points on the International border between Zambia and Malawi. She maintained that the challenge of combating illegal immigrant can be achieved with the improvement of manpower. The study established that much that IOM was helping the DOI in capacity building, the Department lacked manpower to manage the entry and exit points. This had made it easier for cross border crimes such as illegal immigration, human trafficking to go undetected.

There was inadequacy of training of Immigration Officers in identification and differentiating of vulnerable migrants (asylum seekers, refugees, victims of trafficking, unaccompanied and separated children, stateless persons and stranded migrants) resulting in all being treated as illegal immigrants ( Parliamentary Committee Report, 2016). Scolt, (2018) understanding of illegal immigration requires skill technique. John F. Kelly, the White House Chief of Staff in support of immigration policies argued that, the Laws are the Laws as people who elect to enter United States of America illegally should not be entertained. Kelly stressed that people who enter into United States were not bad people, not criminals, not MS-13. But they were also not people that would easily assimilate into US modern society, integrate well, have skills and they were rural people and were costing tax payers more than nature citizens. The Immigration Officers need to be well trained to acquire a skill to deal with such people in technical areas.

\subsection{Absence of migration policy}

The country does not have any migration policy in place. The study also established that immigration/migration laws some are not in line with best international practice. Apart from the Immigration and Deportation Act 18 of 2010 there was no migration framework to regulate the migration especially in border areas. Meanwhile, SADC member states and Zambia in particular can explore African Union Migration Policy Framework for Africa and Plan of Action (2018-2030) which developed from the $74^{\text {th }}$ Ordinary Session held in 2021 of AU Council of Ministers who fostered Migration Policy Framework for Africa and adopted in 2006. However, due to dynamics 
and change in the migration trends and patterns on the African continent, in 2016 MPFAPA (2018-2030) was formulated (AUC Report, 2018)

\subsection{Lack of skill and inadequate capacity in technical area by immigration officers}

The Zambia department of immigration lack technical equipment to improve capacity for fraud detection of false and forged documents among immigration officials which was one of the main challenges to the prevention of risks associated with illegal immigrants, smuggling of migrants and their vulnerabilities, is to have on board the best staff and equipment for the identification of forged travel documents. The equipment is supposed to include a digital microscope, a scanner for alteration detection, magnifying glasses and devices for forensic analysis, UV lights, and computers.

Meanwhile, IOM Development Fund (2012) reported that with a view to improving migration management in the Southern African region, the project embarked to build sustainable capacity of the Zambian Department of Immigration to facilitate regular, and prevent irregular migration. By providing the Department with a manual with clear policy guidelines and Standard Operating Procedures (SOPs), this project will enhance the capacity of immigration officials. Twelve identified officials were trained as trainers, and up to 90 immigration officials were trained in selected training courses, including fraudulent document examination and transnational immigration crime detection.

\subsection{Corruption and bribe among security Agents and members of the community}

Mikhnovets (2018) quotes (Johnson 2005, p11) that one of the definitions of corruption implies "the abuse of a trust, generally one involving public power for private benefit which often, but by no means always, come in the form of money".

Corruption in its various expressions and forms has been a notion that has known no border limitation. Officials, who are expected to combat the illegal immigration and other cross border crimes as the best way of executing their duties, sometimes perpetuate the vice. Some respondents in state custody indicated that there was a syndicate in Tanzania involving Border Control Officers in connivance with Zambian Immigration Officers who were dubiously acquiring Identity Documents (IDs) for illegal immigrants at a fee of fifty thousand (50 000) Tanzanian Shilling cash per person. These maneuvers by Officials entrusted to regulate the movements and stay of people defeats the objective of Government to prevent the illegal entry into Zambia.

The study also established that some illegal immigrants were bribing some Zambians to harbor them in their houses while others were being bribed not to disclose their presence. Frank (2018) indicated that corruption forms an integral feature of immigration policing in Malaysia and how migrants tactically use the practice of bribery to avoid arrests and consequent deportation. Corruption influences immigrant's ability to retain "invisibility" from the state.

Mortensen (2009) pointed out that eighty three per cent (83\%) of Americans view Government's corruption as very important problem. The author stress that most illegal aliens in USA come from countries where corruption was rampant. Corruption involved in virtually everything illegal aliens do. They either sneak into the United States or lie to Consular and Immigration Officials in order to obtain Visas and legal entry.

\subsection{Inadequate sensitization of security personnel, Cross border traders and international drivers about illegal immigrants.}

Some of the cross border trader and trans-border drivers expressed ignorance about the who to report to of the immigrants they see and sometimes give a lift to. The issue was attributed to lack of sensitization by the persons and institutions mandated to combat the vice. This can be through community adverts, pictures and holding of public forums.

\section{Conclusion}

SADC states have a long history of intra-regional migration, dating back to the mid-nineteenth century. Migration was probably the single most important factor tying together all of the various colonies and countries of the sub-continent into a single regional labor market during the twentieth century. Analyzing the inflow of illegal immigrants to Zambia, this study concludes that there are practical factors why the scourge was happening. Africa where SADC belongs is a continent full of conflict, political instability, economic instability, natural disasters; these factors in most instance act as push factors which motive the citizens to migrate whenever, there was any atrocities. Zambia was grappling with illegal immigration either as transiting or destination owing to its geographical set up as a land linked state. The country has been a haven of peace since independence in 1964 , therefore, citizens of neighboring countries engulfed in political, economic or social turmoil found it safe to flee to Zambia.

Some of the illegal immigrants in the hope of securing business or employment opportunities decide to use orthodox means to cross into Zambia, to which others use un-gazette routs, forge travel documents after bribing 
or corrupting some people. The country had no migration policy in place to supplement the Immigrations and Deportation Act 18 of 2010. The lack of migration policy and political will to fund the ministries responsible more adequately was also a challenge faced by Zambia to combat the vice, because security agents were compelled to be compromised with bribery of corruption due lack of funding.

\section{References}

AUC Report, (2018). African Union Migration Policy Framework for Africa and Plan of Action (2018-2030).

Beck, J. (2017). Cosmopolitanism, Communitarianism and Immigration. USA. Retrieved from www.numbersusa.cpm/blog/cosmopolitanism.

Burroughs, E. (2012). Irish Institutional Discourse of Illegal Immigration: A critical Discourse Analysis Approach. NIRSA

Buzan,B; Held,D \& McGrew, A .(1998). Realism vs Cosmopolitanism Review of International Studies 24 (3), pp 387-398. Doi 10.1017/S02/00210598003878.

Campbell, K. Eugene. (2006). Reflection on illegal immigration in Botswana and South Africa. African Population Studies. Union for Africa Population Studies Vol. 21 No. 2, 2006, pp. 23-44

Cavallar, G. (2012). Cosmopolitanisms in Kant's Philosophy, Ethic \& Global Politics, 5:2 95-118, doi: 10.3402/egp.v5i2.14924. Roulledge Taylor 7 Francis Group.

Delanty G. (2006). The Cosmopolitan imagnation critical cosmopotilanism and social theory. The British Joural of Sociology 2006 volume 57 issue.

Drezner, W. D (2008). The Realist Traditional in American Public Opinion. Pespective on Politics vol 16, No 1 pp. 51-70. American Political Science Associat: USA. Retrieved from https://www.jstor.org/stable/20446637.

Etzioni, A.(2015). Communitarianism-Institute for Communitarian Police Studies. Retrieved from https://icps.gwu.edu/sites/g/files/zaxdzs1736/f/1----/communitarianism.Etzion.pl.

Immigration and Deportation Act, No. 18 of 2010165.

Institute for Security Studies ISS (2009). 2A Crime in Zambia. The Criminal Justice System in Zambia. Enhancing the Delivery of Security in Africa.

Isoke, H (2015). The Dilemma of porous Borders. Uganda's Experience in Combating Terrorism.

Kinbacher, K. (2006). Immgration, The American West, and the Twentieth Cedntury: German from Russia, Omaha Indian, and Vietnamese-Urban Villagers in Lincoln, Nebraska. Lincoln. Retrieved from https://digital commons.un/.edu/cgi/view content,cgi?article=1000\&content.

Mark R. Amstulz. (2015). Two Theories of Immigration

Mikhnovets, I .(2018). Academic study on the potential Nexus between Corruption and Migration: The case of Foreed and Irregular Migrants in Sweden IACA Research Paper Series No.08.

Mortensen. W. Ronald. (2009). Illegal immigration: A Culture of Corruption. Centre for Immigration Studies.

National Security and Foreign Affairs Republic of Zambia Report of the Committee for the First Session of the Twelfth National Assembly appointed on $6^{\text {th }}$ October, 2016.

Nkurayija, C.J. (2011). Impact of Globalisation on Africas' Development: "Rwanda Tourism as Key to Mobilize Revenue and Investment". National University of Rwanda: Rwanda.

Rohif, M. (2010). Immanuel Kant. Standford Encyclopedia of Philosophy. Retrieved from https://plato.standford.edu/entries/kant/ on 17/07/19

Scoth, E. (2018). John Kelly’s ‘Assimilation' into a Hard Line Stance Against Illegal Immigrants.

Solomon .H. (2000) contemplating the impact of illegal immigration on the Republic of South Africa.

Steger, B. M. (2011). The Rise of the Global Imaginary: Political ideologies from the French Revolution to the Global War on Terror. Oxford University Press: UK. Doi: 10.1093/acprof:oso/9780199286942.001.001.

The Time of Zambia, $6^{\text {th }}$ august, 2014. Is Zambia a safe Haven of illegal immigrants.

Thet,K.K .(2015). Pull and Push factors of Migration: A Case Study in the Urban area of Monywa Township, Myammar. Retrieved from https://www.worldofstatistic.org/files/---/pull--and push Factors-of migrationThet.pdf.

Times of Zambia, August 14, 2014. Are Zambia's Borders so porous? Retrieved March 28, 2019 at 12:00 hours. Zambia Daily Mail, Septemebrs $7^{\text {th }}, 2016.77$ illegal immigrants deported.

Zurn, M \& Wilde de, P. (2016). Debating globalization: Cosmopolitanism and Communitarianism as Political ideologies. Journal of Political Ideologies volume 21, 2016 - issue 3 page 280-301. Retrieved from https:// doi.org/10.1080/13569317.2016.1207741. 